\title{
Successful preterm pregnancy in a rare variation of Herlyn-Werner-Wunderlich syndrome: a case report
}

\author{
Stefania Cappello ${ }^{1 *}$ (D) Eleonora Piccolo ${ }^{1}$, Francesco Cucinelli ${ }^{2}$, Luisa Casadei ${ }^{1}$, Emilio Piccione ${ }^{1}$ and \\ Maria Giovanna Salerno ${ }^{2}$
}

\begin{abstract}
Background: Herlyn-Werner-Wunderlich syndrome (HWWS) is an uncommon congenital anomaly of the female urogenital tract, characterised by uterus didelphys, obstructed hemivagina, and ipsilateral renal agenesis. We reported the difficult pregnancy course complicated by an extremely rare and unique case of this syndrome associated with ectrodactyly, a clinical combination never described in literature.

Case presentation: A 28- year-old nulliparous woman previously diagnosed for HWWS associated with ectrodactyly of the right foot and with a history of abdominal left hemi-hysterectomy, ipsilateral salpingectomy, vaginal reconstruction when she was an adolescent. She suffered from threats of abortion in the first trimester, recurrent urinary tract infections during all pregnancy. At 33 weeks +5 days of gestational age, she was hospitalized for premature rupture of the membranes and uterine contractions and a caesarean section was performed because of breech presentation. Postpartum period was complicated by a pelvic abscess resolved with parental antibiotic therapies.

Conclusions: Our literature review shows an unusual aspect in our case: HWWS is not classically associated with skeletal anomalies. Moreover, the most frequent urogenital side affected is the right, not left side as in this woman. Preterm spontaneous rupture of membranes and fetal abnormal presentation represent frequent complications and probably post-caesarean infections are related to pregnancies in the context of this syndrome.
\end{abstract}

Keywords: Herlyn-Werner-Wunderlich syndrome (HWWS), OHVIRA syndrome, Müllerian duct anomalies, Ectrodactyly, Renal agenesis, Utero didelphys, Obstructed hemivagina, Pregnancy

\section{Background}

Herlyn -Werner-Wunderlich syndrome (HWWS) is a rare congenital anomaly of the female genital tract, characterised by the triad of uterus didelphys, blind hemivagina, and ipsilateral renal agenesis $[1,2]$. It is even called OHVIRA syndrome (obstructed hemivagina, ipsilateral renal anomaly) and it is a result of the arrest of the midline fusion of the Müllerian ducts. This condition was first described in 70's and the incidence is low and probably underestimated [3]. Usually the diagnosis comes during adolescence due to hematocolpos, the frequent urinary tract infections or the presence of a pelvic mass

\footnotetext{
* Correspondence: steficappello@gmail.com

${ }^{1}$ Department of Biomedicine and Prevention, Obstetrics and Gynecological

Clinic, University of Rome "Tor Vergata", via Montpellier 1, 00133 Rome, Italy

Full list of author information is available at the end of the article
}

$[4,5]$. Although all the Müllerian anomalies are related to infertility, frequent miscarriage, obstetric complications including abnormal fetal presentation, intrauterine growth restriction, and increased rate of caesarean section as well as abruptio placentae, premature rupture of membranes, retained placenta, postpartum haemorrhage, and increased fetal mortality [6, 7]. We presented a case of an unusual variant of HWWS associated with ectrodactyly [8] of the right foot, a combination never described [9], and the difficult course of her first preterm pregnancy with a particular postpartum complication. We are not sure if the ectrodactyly is an incidental finding or there is a causal effect with the disease, because it was not described by literature before.

(c) The Author(s). 2018 Open Access This article is distributed under the terms of the Creative Commons Attribution 4.0 International License (http://creativecommons.org/licenses/by/4.0/), which permits unrestricted use, distribution, and reproduction in any medium, provided you give appropriate credit to the original author(s) and the source, provide a link to the Creative Commons license, and indicate if changes were made. The Creative Commons Public Domain Dedication waiver (http://creativecommons.org/publicdomain/zero/1.0/) applies to the data made available in this article, unless otherwise stated. 


\section{Case Presentation}

A 28 year-old nulliparous woman, previously diagnosed for HWWS, was referred to San Camillo-Forlanini Hospital during her third spontaneous pregnancy. The clinical history of our patient began when at her birth, the ectrodactyly of the right foot (absence of the 2 medial rays), immediately became apparent. The karyotype analysis was normal 46 $\mathrm{XX}$. At age 1, she underwent a surgical correction of this anomaly with consequent partial improvement of a functional deficiency. An upper abdominal ultrasound, performed after a history of recurrent urinary tract infections and pyelonephritis, revealed the absence of the left kidney and the right megaureter. At 12 years, after 2 months from menarche, due to severe acute pelvic pain, a pelvic ultrasound and a magnetic resonance imaging (MRI) were performed. MRI showed a left blind hemivagina with hematocolpos, uterus didelphys with hematometra in the left hemiuterus and ipsilateral hematosalpinx. These imaging findings were later confirmed by the diagnostic laparoscopy which showed normal right uterus, right fallopian tube and both regular ovaries. Consequently, she underwent a surgical reconstruction of the vagina consisting in the drainage of hematocolpos and the removal of the vaginal septum, whereas an abdominal left hemi- hysterectomy and ipsilateral salpingectomy were performed through a Pfannenstiel incision. Her obstetric history was significant for two spontaneous abortion at the age of 26 , occurred at 7th and 12th weeks respectively. She had no problem of fertility in anamnesis. The woman came to our observation for the first time at 15 weeks of pregnancy for abortion threats resolved with vaginal progesterone. Singleton fetus was anatomically in the norm. The patient had a moderate protenuria of $1400 \mathrm{mg}$ in 24 hours, so she started a proper diet and a monitor of urine proteins. Close and regular surveillance (clinical, laboratory, and ultrasound) was initiated. The obstetric ultrasound controls revealed adequate growth of a fetus without major malformations, and normal Doppler indices of the fetal, feto-maternal and utero-placental vessels. During the three trimesters, frequent urinary infections occurred that were appropriately treated after urine culture and antibiogram test. At 33 weeks +5 days of gestational age she was admitted to our hospital for premature spontaneous rupture of membranes (pPROM): she reported light amniotic fluid leak one hour before our observation. The admission assessment detected a reduced amniotic fluid index, a regular fetal growth and posterior placenta in the norm; the umbilical artery Doppler values were in the range, the fetal cardiac monitoring was regular and uterine contractions were present. The vaginal examination revealed a soft cervix, $80 \%$ effaced, dilated about $2 \mathrm{~cm}$, and the fetus was in breech at station -3 . The ultrasound cervical length was $24 \mathrm{~mm}$. A single course of antenatal corticosteroid therapy for fetal lungs maturity induction and tocolytic drugs were administered. On the second day of hospitalization, an emergency caesarean section was performed because the cervix was modified (dilatation about $4 \mathrm{~cm}$ ), uterine contractility increased while persisting breech presentation (Fig. 1). A female infant was born weighing 2278 gr, with Apgar scores 8/9/9 at 1, 5, and 10 minutes respectively; the umbilical artery ph was 7.35. The placenta weighed 380 grams. The mother and the newborn, made an uncomplicated post-surgical/postnatal course and were discharged on day 3 and 15 respectively. Seventeen days after caesarean section, the woman came back again to our institution for a complaint of asthenia and fever $\left(>38^{\circ} \mathrm{C}\right)$, resistant to paracetamol for five days. On physical examination, she had abdominal tenderness in the lower quadrants and physiological vaginal lochia. Blood exams showed increased leukocyte and inflammatory markers: white blood cells (WBC) were $14,2 \times 10^{3} / \mathrm{ml}$ (range $4,0-10,0 \times 10^{3} / \mathrm{ml}$ ); C-reactive protein (CRP) was $19.98 \mathrm{mg} / \mathrm{l}$ (range $0,01-1 \mathrm{mg} / \mathrm{dl}$ ) and procalcitonin was $0.22 \mathrm{ng} / \mathrm{ml}$ (negative: $<0,05 \mathrm{ng} / \mathrm{ml}$ ). The pelvic ultrasound and the computerized tomography $(\mathrm{CT})$ demonstrated a pelvic abscess neighboring to the lower anterior wall of the uterus with dimensions of $53 \times 47 \mathrm{~mm}$ (Fig. 2). The treatment started immediately and consisted in intravenous antibiotic therapy with Meropenem $500 \mathrm{mg}$ three times a day and lowmolecular weight heparin (LMWH), Enoxaparin 4000 UI subcutaneous daily. Six days after the hospital admission with the right therapy, the inflammatory indices reduced: WBC were $9,8 \times 10^{3} / \mathrm{ml}, \mathrm{PCR}$ was $4.37 \mathrm{mg} / \mathrm{l}$ and procalcitonin was $0.12 \mathrm{ng} / \mathrm{ml}$. After discharge, we started a follow-up to assess the clinical conditions of our patient: she was

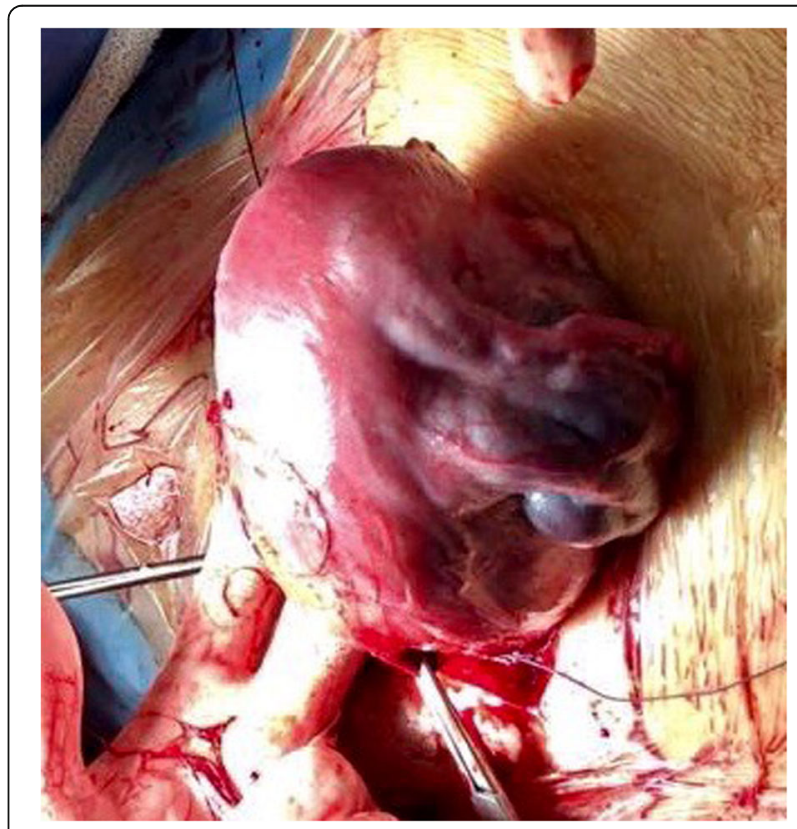

Fig. 1 Uterus at the time of caesarean delivery 


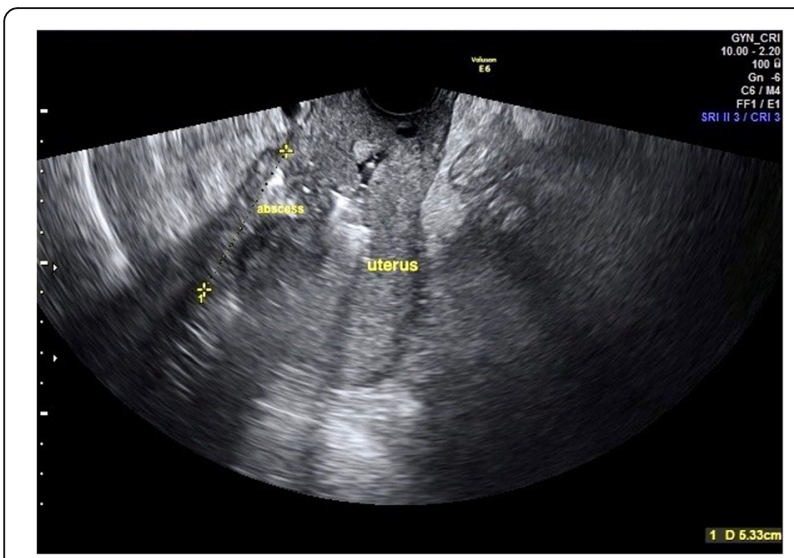

Fig. 2 Pelvic Abscess at the ultrasound imaging. Abscess neighboring to the lower anterior wall of the uterus with dimensions of $53 \times 47 \mathrm{~mm}$

asymptomatic, her blood exams were within normal ranges and the pelvic abscess was significantly decreased. Histopathologic examination of the placenta and umbilical cord obtained after about 40 days, not identified signs of chorioamnionitis and/or funisitis.

\section{Discussion}

Müllerian duct anomalies affect 2-3\% of women [10]. The combination of uterus didelphys -class III of American Fertility Society -AFS- classification [11] and obstructed hemivagina was described the first time in 1922 [12], then in 70's Herlyn, Werner and Wunderlich reported other similar cases associated with renal anomalies [1, 2]. In 1983 this condition was identified as a syndrome characterised by the triad of uterus didelphys, blind hemivagina and ipsilateral renal agenesis [13]. Since 2007 this syndrome was named with the acronym of OHVIRA syndrome (obstructed hemivagina, ipsilateral renal anomaly), including two of the three of defects of the HWWS, which consists of different uterus anomalies (uterus didelphys or uterus septum) and renal anomalies as well as renal agenesis or polycystic kidney [14-16]. The occurrence of the HWWS seems to be $0.1-3.8 \%$, and it is probably underestimated [3]. HWWS was included in the class U3B uterine anomaly, class $\mathrm{C} 2$ cervix anomaly, and class $\mathrm{V} 3$ vaginal anomaly according to the classification of ESHRE/ESGE [17]. The exact etiology of HWWS is still unclear, but it may be related to an abnormal development of the paraand mesonephric ducts. Didelphys uterus results from the failure of the fusion and differentiation of the Müllerian ducts during the eight week, which should give rise to cervix and uterus [18]. The Wolffian ducts give rise to ureters and kidneys, so when one of these is absent, the ureter and the kidney cannot fuse and the ipsilateral Müllerian duct is lateralized moving away from the urogenital sinus, causing the formation of a blind sac that will correspond to the blind or obstructed hemivagina. The distal portion of the vagina originating from the urogenital sinus is not affected and develops normally. Patients affected by HWWS have no specific symptoms until puberty [5], then they typically present acute pelvic pain, dysmenorrhea, presence of pelvic mass, recurrent urinary tract infections and urinary retention. The diagnosis usually comes in the adolescence, a few years after the menarche, rarely at the birth or during pregnancy $[19,20]$. In fact there is only a case described in literature by Wu et al. of a neonate diagnosed for HWWS presenting as a mass prolapsing per vaginum [21]. Clinical suspicion and early diagnosis are imperative to making a timely treatment to prevent complications such as infertility, endometriosis, pelvic adhesions, pyosalpinx, hemato or pyocolpos, and other obstetrics problems [22]. MRI was considered the gold standard for the diagnosis, but the $3 \mathrm{~d}$ ultrasound plays always a major role for the identification of uterine anomalies [23]. Diagnostic laparoscopy in HWWS should performed only when the diagnosis by imaging is not clear or when MRI is not available [5, 24]. Twenty-five percent of women affected by Müllerian ducts anomalies presents obstetric complications such as recurrent miscarriage, abnormal fetal presentation, postpartum hemorrhage, retained placenta, fetal mortality, fetal growth restriction, premature rupture of membranes [7]. Obstetric outcome of HWWS women was studied after different surgical treatments. These may consist of conservative treatments like the desobstruction of hemivagina, the therapeutic drainage of hematocolpos, the vaginal septotomy and marsupialization; or less conservative interventions like laparoscopic hemi-hysterectomy associated or not with ipsilateral salpingectomy [25-28]. The best treatment of HWWS is controversial but most of the authors conclude that an explorative laparoscopy with vaginal septotomy and drainage of hematocolpos is enough to restore the functionality of both part of the uterus, avoiding hemi-hysterectomy [29, 30]. However, HWWS has good obstetric prognosis: $87 \%$ of pregnancy rate [27], approximately $62 \%$ positive obstetric outcomes without complications during delivery [5, 7]. Haddad reported the reproductive performance of 42 patients with obstructed hemivagina, 9 of whom had 20 pregnancies with $69 \%$ of live births [31]. Heinonen reported the reproductive performance and obstetric complications of 49 patients affected by didelphys uterus finding that the incidence of primary infertility was not significantly increased in these women. The rate of spontaneous miscarriage was $21 \%$, not significantly different from the general population (15-20\%). Preterm birth took place in $24 \%$ of all parts. This rate is higher than that of the general population (9-10\%). Instead the caesarean sections rate is $84 \%$ and it reflects the high incidence of the breech presentation $(51 \%)[29,32]$. In the presentation of this case we drew attention to its rarity because it involves the left part of the body, while usually is the right side affected [28, 33, 34] 
and the association with a malformation of the skeleton of the lower limbs, ectrodactyly of the right foot, was not ever been reported in literature; we found only a case report which described the combination of HWWS and lumbar scoliosis [35] and we are not sure if the skeletal involvement could be only an incidental finding. However, not all authors agree that it is a rarity the involvement of the left side: Yavuz et al. presented a case series of 13 women affected by HWWS and 6 of them had anomalies on the left side of the uro-genital tract [36]. According to the classification proposed by Zhun et al, this case belonged to class 1.1 of HWWS with a complete vaginal obstruction for a blind hemivagina [37] and she had no fertility problems following surgery.

In our experience, we focused on the course and management of the pregnancy complicated of this disorder. The pregnancy we described was at high-risk and the surgical treatment performed during adolescence was the least recommended by literature, however the obstetric outcome was positive thanks to a straight maternal-fetal follow-up. Our case was characterized by two complications of the pregnancy: preterm labour with pPROM and breech presentation, which are frequent in HWWS in literature. Additionally, pPROM was related to uterine anomaly and probably promoted by the frequent infections of urinary tract [38] that may be present in this syndrome, [39], mostly in the pregnant female. The infection occurred post the cesarean section may be caused by the pPROM, the elongate surgery time, the numerous adhesions of the previous surgery, which are known risk factors in post-operative infections [40].

\section{Conclusions}

HWWS is an unusual congenital anomaly with clinical significance and different options for surgical management. An early correct diagnosis and treatment are the goal to relieve symptoms and prevent complications to preserve sexual and reproductive abilities. Despite this, the pregnancies of these women are at an increased risk for unfavorable obstetric outcomes and can be characterized more frequently by complications that must be managed promptly by an accurate and regular maternal and fetal follow-up.

\section{Abbreviations \\ AFS: American Fertility Society; CRP: C-reactive protein; CT: Computed Computed tomographic; ESGE: European Society of Gynecological Endoscopy; ESHRE: European Society of Human Reproduction and Embryology; HWWS: Herlyn-Werner-Wunderlich syndrome; LMWH: Low Low molecular weight heparin; MRI: Magnetic Magnetic resonance imaging; OVHIRA: Obstructed Obstructed hemivagina ipsilateral renal anomaly; pPROM: Premature Premature rupture of membranes; WBC: White White blood cells}

\section{Acknowledgements}

We thank Cinzia Bartolelli M.D and Linda Pirollo M.D for their contribution to the ultrasound imaging; Valeria Lucantoni M.D. and Flavia Pierucci M.D. for the intraoperative documentation.
Funding

Not applicable

Availability of data and materials

Not applicable.

\section{Authors' contributions}

SC, FC and MGS were involved in the management of the pregnancy of the patient. EP1 and LC collected data for the report. SC and EP1 wrote the manuscript. EP2 and MGS were involved in planning and supervised the work. All authors read and approved the final manuscript.

\section{Ethics approval and consent to participate}

This case study was approved by Ethics Committee Lazio 1. Written informed consent was obtained from the patient to take pictures during the surgery for scientific purposes.

\section{Consent for publication}

Written informed consent was obtained from the patient for publication of this work and the images included in the case report.

\section{Competing interests}

The authors declare that they have no competing interests.

\section{Publisher's Note}

Springer Nature remains neutral with regard to jurisdictional claims in published maps and institutional affiliations.

\section{Author details}

${ }^{1}$ Department of Biomedicine and Prevention, Obstetrics and Gynecological Clinic, University of Rome "Tor Vergata", via Montpellier 1, 00133 Rome, Italy. 2Department of Woman's and Child's Health, Obstetrics and Gynecological Unit, San Camillo-Forlanini Hospital, Circonvallazione Gianicolense 87, 00152 Rome, Italy.

Received: 16 February 2018 Accepted: 3 December 2018

Published online: 17 December 2018

References

1. Herlyn U, Werner H. Simultaneous occurrence of an open Gartner-duct cyst, a homolateral aplasia of the kidney and a double uterus as atypical syndrome of abnormalities. Geburtshilfe Frauenheilkd. 1971;31:340-7.

2. Wunderlich M. Unusual form of genital malformation with aplasia of the right kidney. Zentralbl Gynakol. 1976;98(9):559-62.

3. Burgis J. Obstructive Müllerian anomalies: case report, diagnosis, and management. AM J Obstet Gynaecol. 2001;185(2):338-44.

4. Orazi C, Lucchetti MC, Schingo PM, Marchetti $P$, Ferro F. Herlyn-WernerWunderlich syndrome: uterus didelphys, blind hemivagina and ipsilateral renal agenesis. Sonographic and MR findings in 11 cases. Pediatr Radiol. 2007;37(7):657-65

5. Del Vescovo R, Battisti S, Di Paola V, Piccolo CL, Cazzato L, Sansoni I, Grasso RF, Beomonte Zobel B. Herlyn -Werner-Wunderlich syndrome: MRI findings, radiological guide (two cases and literature review), and differential diagnosis. BMC Med Imaging. 2012;12:4.

6. Shavell VL, Montgomery SE, Johnson SC, Diamond MP, Berman JM. Complete septate uterus, obstructed hemivagina, and ipsilateral renal anomaly: pregnancy course complicated by a rare urogenital anomaly. Arch Gynaecol Obstet. 2009;280:449-52.

7. Afrashtehfar CD, Pigña-García A, Afrashtehfar Kl. Müllerian anomalies. Obstructed hemivagina and ipsilateral renal anomaly syndrome (OHVIRA). Cir Cir. 2014;82(4):460-71.

8. Jindal G, Parmar VR, Gupta VK. Ectrodactyly/split hand feet malformation. Indian J Hum Genet. 2009;15(3):140-2.

9. Hydir Z, Beale V, O'Connor R, Clayton-Smith J. Genitourinary malformations: an under-recognized feature of ectrodactyly, ectodermal dysplasia and cleft lip/palate syndrome. Clin Dysmorphol. 2017;26(2):78-82.

10. Lin PC, Bhatnagar KP, Nettleton S, Nakajima ST. Female genital anomalies affecting reproduction. Fert Steril. 2002;78(5):899-915.

11. American Fertility Society. The American Fertility Society classification of adnexal adhesions, distal tubal occlusion, tubal occlusion secondary to tubal 
ligation, tubal pregnancies. Müllerian duct anomalies and intrauterine adhesions. Fert Steril. 1988:49:944-55.

12. Purslow CE. A case of unilateral haematocolpos, hematometra and haematosalpinx. J Obstet Gynaecol Br Emp. 1922;29:643.

13. Karag'ozov I. Herlyn -Werner-Wunderlich syndrome. Akush Ginekol (Sofiia). 1983;22(1):70-6.

14. Smith NA, Laufer MR. Obstructed hemivagina and ipsilateral renal anomaly (OHVIRA) syndrome: management and follow-up. Fert Steril. 2007:87(4):918-22.

15. Živković K, Prka M, Živković N, Bucko A, Habek D. Unusual case of OHVIRA syndrome with a single uterus, unrecognized before labor and followed by an intrapartum rupture of obstructed hemivagina. Arch Gynaecol Obstet. 2014;290:855-8.

16. Han B, Herndon CN, Rosen MP, Wang ZJ, Daldrup-Link H. Uterine didelphys associated with obstructed hemivagina and ipsilateral renal anomaly (OHVIRA) syndrome. Radiol Case Rep. 2015;5(1):327.

17. Grimbizis GF, Gordts S, Di Spiezio Sardo A, Brucker S, De Angelis C, Gergolet M, Li TC, Tanos V, Brölmann H, Gianaroli L, Campo R. The ESHRE-ESGE consensus on the classification of female genital tract congenital anomalies. Gynecol Surg. 2013;10(3):199-212.

18. Vercellini $P$, Daguati $R$, Somigliana $E$, Viganò $P$, Lanzani $A$, Fedele $L$. Asymmetric lateral distribution of obstructed hemivagina and renal agenesis in women with uterus didelphys institutional case series and a systematic literature review. Fert Steril. 2007;87(4):719-24.

19. Muraoka A, Tsuda H, Kotani T, Kikkawa F. Severe hemoperitoneum during pregnancy with obstructed hemivagina and ipsilateral renal anomaly syndrome: a case report. J Reprod Med. 2016;61:290-4.

20. Reis MI, Vicente AP, Cominho J, Gomes AS, Martins L, Nunes F. Pyometra and pregnancy with Herlyn -Werner-Wunderlich syndrome. Rev Bras Ginecol Obstet. 2016;38(12):623-8.

21. Wu T-H, Wu T-T, Ng Y-Y, et al. Herlyn-Werner-Wunderlich syndrome consisting of uterine didelphys, obstructed hemivagina and ipsilateral renal agenesis in a newborn. Pediatr Neonatol. 2012;53:68-71.

22. Bhoil R, Ahluwalia A, Chauhan N. Herlin Werner Wunderlich syndrome with hematocolpos: an unusual case report of full diagnostic approach and treatment. Int J Fert Steril. 2016;10(1):136-40.

23. Gungor Ugurlucan F, Bastu E, Gulsen G, Kurek Eken M, Akhan SE. OHVIRA syndrome presenting with acute abdomen: a case report and review of the literature. Clin Imaging. 2014;38(3):357-9.

24. Jeong J-H, Kim YJ, Chang C-H, Choi H-I. A case of Herlyn- WernerWunderlich syndrome with recurrent hematopyometra. J Women's Med. 2009;2(2):76-80.

25. Stassart JP, Nagel TC, Prem KA, Phipps WR. Uterus didelphys, obstructed hemivagina, and ipsilateral renal agenesis: the University of Minnesota experience. Fert Steril. 1992;57(4):756-61.

26. Monks P. Uterus didelphys associated with unilateral cervical atresia and renal agenesis. Aust N Z J Obstet Gynaecol. 1979;19(4):245-6.

27. Candiani GB, Fedele L, Candiani M. Double uterus, blind hemivagina, and ipsilateral renal agenesis:36 cases and long-term follow-up. Obstet Gynaecol. 1997;90(1):26-32

28. Chen FP, Ng KK. Term pregnancy at the site of atresia following vaginal canalization in a case of uterus didelphys with hemivaginal atresia and ipsilateral renal agenesis. Taiwan J Obstet Gynaecol. 2006;45(4):366-8.

29. Cozzolino M, Corioni S, Magro Malosso ER, Sorbi F, Mecacci F. Two successful pregnancies in Herlyn -Werner-Wunderlich syndrome. J Obstet and Gynaecol. 2014;34(6):534-5.

30. Altchek A, Paciuc J. Successful pregnancy following surgery in the obstructed uterus in a uterus didelphys with unilateral distal vaginal agenesis and ipsilateral renal agenesis: case report and literature review. J Pediatr Adolesc Gynaecol. 2009;22(5):e159-62.

31. Haddad B, Barranger E, Paniel BJ. Blind hemivagina: long-term follow -up and reproductive performance in 42 cases. Hum Reprod. 1999;14(8):1962-4.

32. Heinonen PK. Clinical implications of the didelphic uterus: long-term followup of 49 cases. Eur J Obstet Gynecol Reprod Biol. 2000;91 (2):183-90.

33. Adair $\mathrm{L}$ 2nd, Georgiades M, Osborne R, Ng T. Uterus didelphys with unilateral distal vaginal agenesis and ipsilateral renal agenesis: common presentation of an unusual variation. J Radiol Case Rep. 2011;5(1):1-8.

34. Singh K, Thakur S, Soni A, Verma A. Herlyn-Werner-Wunderlich syndrome/ OHVIRA syndrome; a rare urogenital anomaly with unusual presentation in two case with review of literature. Clinics Mother Child Health. 2016;13(1):1-4.

35. Li Z, Yu X, Shen J, Liang J. Scoliosis in Herlyn-Werner-Wunderlich syndrome: a case report and literature review. Medicine (Baltimore). 2014;93(28):e185.
36. Yavuz A, Bora A, Kurdoğlu M, Goya C, Kurdoğlu Z, Beyazal M, Akdemir Z. Herlyn-Werner-Wunderlich syndrome: merits of sonographic and magnetic resonance imaging for accurate diagnosis and patient management in 13 cases. J Pediatr Adolesc Gynecol. 2015;28(1):47-52.

37. Zhun L, Chen N, Tong JL, Wang W, Zhang L, Lang JH. New classification of Herlyn -Werner-Wunderlich syndrome. Chin Med J (Engl). 2015;128(2):222-5.

38. Karat C, Madhivanan P, Krupp K, Poornima S, Jayanthi NV, Suguna JS, Mathai $E$. The clinical and microbiological correlates of premature rupture of membranes. Indian J Med Microbiol. 2006;24(4):283-5.

39. Tsai JL, Tsai SF. Case Report: A Rare Cause of Complicated Urinary Tract Infection in a Woman with Herlyn-Werner-Wunderlich Syndrome. Iran Red Crescent Med J. 2016;18(11):e40267.

40. Kawakita T, Landy HJ. Surgical site infection after cesarean delivery: epidemiology, prevention and treatment. Maternal Health Neonatol Perinatol. 2017;3:12.
Ready to submit your research? Choose BMC and benefit from:

- fast, convenient online submission

- thorough peer review by experienced researchers in your field

- rapid publication on acceptance

- support for research data, including large and complex data types

- gold Open Access which fosters wider collaboration and increased citations

- maximum visibility for your research: over $100 \mathrm{M}$ website views per year

At BMC, research is always in progress.

Learn more biomedcentral.com/submissions 